\title{
Earth Surface Processes and Landforms $\quad$ BSG_end
}

\section{A laboratory study of Equotip surface hardness measurements on a range of sandstones: what influences the values and what do they mean?}

\begin{tabular}{|r|l|}
\hline Journal: & Earth Surface Processes and Landforms \\
\hline Manuscript ID & ESP-18-0294.R2 \\
\hline Wiley - Manuscript type: & Research Article \\
\hline Author: & 11 -Jan-2019 \\
\hline Complete List of Authors: & $\begin{array}{l}\text { DESARNAUD, julie; Getty Conservation Institute, Science } \\
\text { Kiriyama, Kyoko; university of KYOTO, Graduate School of Advanced } \\
\text { Integrated Studies } \\
\text { Bicer-Simsir, Beril; Getty Conservation Institute, Science } \\
\text { Wilhelm, Katrin; University of Oxford, School of Geography and the } \\
\text { Environment } \\
\text { Viles, Heather; University of Oxford, School of Geography and the } \\
\text { Environment; }\end{array}$ \\
\hline Keywords: & $\begin{array}{l}\text { Rebound test, surface hardness, Sandstone, moisture content, surface } \\
\text { roughness }\end{array}$ \\
\hline &
\end{tabular}

\section{SCHOLARONE" \\ Manuscripts}




\begin{abstract}
A laboratory study of Equotip surface hardness measurements on a range of sandstones: what influences the values and what do they mean?

Julie Desarnaud*1, Kyoko Kiriyama², Beril Bicer Simsir ${ }^{1}$, Katrin Wilhelm ${ }^{3}$, Heather Viles ${ }^{3}$

${ }^{1}$ Getty Conservation Institute, 1200 Getty Center Drive, Suite 700. Los Angeles, CA 90049. USA

${ }^{2}$ Graduate School of Advanced Integrated Studies in Human Survivability, Kyoto University, Nakaadachi-cho, Yoshida, Sakyo-ku, Kyoto 606-8306, JAPAN

${ }^{3}$ School of Geography and the Environment, University of Oxford, South Parks Road, Oxford, OX1 3QY, UK.
\end{abstract}

\title{
1. Introduction
}

The Equotip hardness tester is a versatile, field-portable piece of equipment originally designed for testing metal hardness which has also become popular for non-destructive, rapid assessments of the surface hardness of rocks and building materials (Verwaal and Mulder, 1999; Aoki and Matsukura, 2007; Viles et al., 2011; Menéndez, 2016). Surface hardness measurements are often made as part of geomorphological studies into the degree and rate of rock weathering and stone deterioration (André et al., 2014; Wilhelm et al., 2016a) and assessments of the performance of conservation materials such as consolidants (Perez Ema and Bustamente Montoro, 2013; Zornoza-Indart and LopezArce, 2016). Measuring surface hardness is a quick, easy and non-destructive way of estimating compressive strength and, by implication, of providing information on the weathering status, exposure age and history of a rock or building surface. The Equotip has recently been used in geomorphological research on topics including the erosion of coastal engineering structures (Coombes et al., 2013), shore platforms (Feal-Pérez and Blanco-Chao, 2013) and the weathering history of limestone gravestones (Wilhelm et al., 2016a).

Despite the popularity of the Equotip and other similar rebound devices to measure rock and stone surface hardness, there are no standards for generating Equotip data on these materials, although several papers have proposed different methods of data collection, index calculation and statistical analyses (e.g. Yilmaz, 2013; Wilhelm et al., 2016b; Asiri et al., 2016; Corkum et al., 2018). Standards exist for the Schmidt Hammer (e.g. ASTM 
D5873-14) but are not directly applicable to the Equotip. Furthermore, whilst several investigations have been made of the relationship between surface hardness measurements and compressive strength of building stones (e.g. Meulenkamp and Grima, 1999; Aoki and Matsukura, 2008; Aly et al., 2016; Wedekind et al., 2016), there is no clear agreement over what Equotip values mean in terms of mechanical properties.

In order for Equotip surface hardness data to be a useful discriminator of the degree of weathering and the impact of consolidant treatments, it is important to explore (a) adequate sampling to produce reliable data, (b) potential sources of variability in Equotip results, (c) whether the Equotip impacts cause irreversible and noticeable damage, and (d) what Equotip hardness values tell us about surface and near-surface strength and other mechanical characteristics. This paper addresses these issues.

There are several Equotip hardness testing device models, all consisting of a probe containing a rebound impact body and a recording unit. A range of probes are available with different impact energies and geometries, but the $D(11.5 \mathrm{Nmm}), \mathrm{DL}(11.1 \mathrm{Nmm})$ and $\mathrm{C}(3 \mathrm{Nmm})$ are the most commonly used probes in research on geomorphology and stone conservation (Torok and Prikryl, 2010, Wedekind et al., 2016, Wilhelm et al., 2016a). Few studies have been made of the relative advantages or disadvantages of the different probes. Several factors have been reported to affect Equotip hardness measurements on samples of rocks and building stones, including proximity to the edge of blocks, block dimensions (including thickness), moisture contents, porosity and surface roughness. Most studies recommend avoiding taking measurements too close to the edge of blocks. For example, Coombes et al., (2013) only took measurements more than $10 \mathrm{~mm}$ away from the edge of blocks of limestone, concrete and granite. A field experimental study by Viles et al., (2011) on large blocks of sandstone showed no evidence of edge effects for the Equotip as compared with the Schmidt Hammer. However, it is not clear whether edge effects depend on block size, material characteristics, or the impact energy of the probe used. The influence of block dimensions (in particular block thickness) is also debated. Verwaal and Mulder (1993) suggest that blocks of $>50 \mathrm{~mm}$ in thickness produce reliable results, whilst Asiri et al., (2016) found that for both core and cubic specimens of Wallace Sandstone from Nova Scotia, Canada 
volumes of $100 \mathrm{~cm}^{3}$ or higher produced reliable data. Viles et al. (2011) investigated sandstone clasts in the field with volumes ranging from $200 \mathrm{~cm}^{3}$ to almost $20000 \mathrm{~cm}^{3}$ and found no significant relationship between Equotip values and boulder volume. Little research has been done on whether Equotip data is influenced by the moisture contents of the materials tested. Viles et al. (2011) collected field data on sandstone surfaces and found some limited evidence of lower values on wet vs dry surfaces, whilst Asiri et al. (2016) suggest that Equotip measurements are not affected by moisture.

Surface roughness is thought to have a strong impact on Equotip values. The manufacturers recommend that for metal surfaces the maximum surface roughness depth $\left(R_{t}\right)$ should not exceed 10 microns for the $D$ probe and 2.5 microns for the $C$ probe. However, empirical data collected on stone and rock surfaces shows variable results. Verwaal and Mulder (1993) found no significant difference in Equotip values from laboratory specimens of limestone prepared with four different treatments to give surfaces of varying roughness, nor did Okawa et al. (1999). In contrast, Feal-Pérez and BlancoChao (2013) find that surface roughness affected Equotip measurements on coastal shore platforms (rougher surfaces generating lower $L$ values). Testing on a range of naturally weathered sandstone surfaces before and after smoothing with carborundum by Viles et al. (2011) indicated higher Equotip hardness values on the smoother surfaces, but it is hard to know whether this resulted from decreasing surface roughness or the removal of a weaker, weathered surface layer (or a combination of the two).

Whilst the Equotip has a much lower impact energy than the Schmidt Hammer (type L Impact energy $735 \mathrm{Nmm}$ and type N $2207 \mathrm{Nmm}$ ), it is still potentially able to leave small impact marks on stone surfaces where plastic deformation occurs. For geomorphological applications this is normally not a problem given the small probe diameter $(3 \mathrm{~mm})$ relative to the scale of most landscape features, but for heritage science applications when working on valuable carvings and stonework this could be unacceptable. To our knowledge, no previous studies have investigated such issues.

Given the non-destructive, quick and relatively cheap nature of the Equotip, several researchers have investigated whether it produces useful proxy data for unconfined compressive strength (UCS), or elastic properties (Aoki and Matsukura, 2008) of stone 
and thus might obviate the need for expensive test methods which require large samples to be taken. Previous studies have produced different empirical relationships between UCS and Equotip hardness data (sometimes including density or porosity as well) for a range of rock types (Kawasaki et al., 2000; Aoki and Matsukura, 2007; Yilmaz, 2013; Asiri et al., 2016). Corkum et al. (2018) present a good summary and compilation of these and conclude that power functions provide the best fit, with different coefficients for different rock types.

In this paper we report on an evaluation of Equotip data collected with $\mathrm{D}$ and $\mathrm{C}$ probes in the laboratory, on fresh blocks cut from four sandstones of varying properties, all commonly used as building stones (Stanton Moor Sandstone, UK; Locharbriggs Sandstone, UK; Ohio Sandstone, USA and Prague Sandstone, Czech Republic). This study is part of a larger investigation which aims to develop a robust method for evaluating the performance of surface treatments on deteriorating sandstones. In particular, after an evaluation of the sample size required for reliable Single impact method (SIM) measurements, we explore the influence of block dimensions, material moisture conditions (wet or dry) and surface roughness on Equotip data using both SIM and Repeated impact methods (RIM). We also investigate any surface damage caused by the Equotip, and the relationships between Equotip data, porosity and compressive strength. Finally, we explore the differences between data from $C$ and $D$ probes, and their advantages and disadvantages for different applications.

\section{Materials and methods}

Four sandstones, one from the USA and the others from Europe were chosen to represent a cross-section of sandstone types. We have selected sandstones commonly used in built heritage around the world which cover the 3 classes of sandstone porosity (Siegesmund and Snethlage, 2011), are all dominantly composed of quartz grains, with some additional minerals and with differing amounts of clay within the matrix (table 1).

Stanton Moor (SM): A Carboniferous sandstone (359-299 Ma) mainly quartz to subarkose arenite in nature, extracted from Dale View quarry, Matlock, England. It is a medium grain size $(228 \pm 91 \mu \mathrm{m})$, poorly sorted and a mineralogically immature bluff sandstone composed of detrital sub-angular quartz grains, feldspar (albite) and muscovite. The latter 
decompose into clay (Kaolinite), reducing the porosity (clay content $<2 \%$ ). The stone has small pores, and a unimodal pore size distribution with a porosity of $12.9 \%$. Quartz and calcite cement are common throughout, with quartz cement commonly occurring as quartz overgrowths.

Ohio Sandstone (OH): Quartz arenite, early Mississippian (350 Ma), quarried in Ohio, US. It is composed mostly of poorly sorted medium size quartz grains $(230 \pm 84 \mu \mathrm{m})$ with small percentages of feldspar, Fe-oxide, muscovite and clay (3.5\% - Kaolinite and Illite) with silica cement. It is an isotropic stone with a unimodal pore size distribution and a porosity of $20 \%$.

Locharbriggs (LB): Lower Permian age (299-251 Ma), quartz arenite, quarried in Locharbriggs quarry, Dumfries and Galloway, southern Scotland. It is a red sandstone, of medium grain size $(193 \pm 90 \mu \mathrm{m})$ containing mainly sub-rounded quartz grains, of variable shape and size with most having hematite rims and quartz overgrowth. A small percentage of feldspar grains is also found. There is a strong and distinguishable fabric with narrow layers of poorly sorted quartz grains with minor amounts of iron oxide and small pores separated by layers composed of larger quartz grains and larger pores. It has a unimodal pore size distribution with a porosity of $23.4 \%$. The clay content is $3.75 \%$ (mainly Kaolinite, Illite and Smectite group - i.e. expanding clays).

Mšené (Prague) Sandstone (PS): Cretaceous age (Cenomanian 93-105 Ma) quartz arenite obtained from the Mšené la'zne quarry, Czech Republic. It is a fine-grained sandstone $(130 \pm 62 \mu \mathrm{m})$ mainly composed of sub-rounded quartz grains, with other accessory minerals including muscovite. It has a high matrix clay content (8\% - mainly kaolinite), and high porosity (28.9\%) with a unimodal pore size distribution and a high connectivity. Cementation is mainly clay, no quartz overgrowths.

Each sandstone was obtained fresh from the quarry and cut into blocks of varying size and shape for the different experiments reported below. Additionally, for some of the experiments four other sandstone types were also studied (two from the USA - Bluff sandstone from Utah, and Red Sandstone from Arizona, and two from Germany - Sander Graser and Wustenzeller sandstone). 


\subsection{Surface hardness measurements}

The hardness of a material is quantified as the resistance of the material to an impacting device. In this research, surface hardness has been studied using the dynamic rebound testing method according to Leeb, with a rebound device (Proceq Equotip 550). The device measures both the impact and rebound velocity of a hard spherical impact body traveling in a probe and propelled by spring force against the surface (Proceq@ SA, 2010). Before and after impact, a permanent magnet inside the impact body passes through a coil inducing a voltage signal proportional to velocity (Frank et al., 2002). The hardness $\left(\mathrm{HL}\right.$ - expressed in Leeb Hardness unit is calculated from the ratio of rebound velocity $\left(v_{r}\right)$ and impact velocity $\left(v_{i}\right)$, (Leeb, 1978) in equation (1):

$H L=\frac{\mathrm{Vr}}{\mathrm{Vi}} \cdot 1000$

The Equotip can be used with a range of different probes. In this study, Probe $D$ and Probe $C$ have been used. Both are composed of a tungsten impact body with a diameter of $3 \mathrm{~mm}$ and present an impact energy of $11.5 \times 10^{-3} \mathrm{Nm}$ and $3 \times 10^{-3} \mathrm{Nm}$, respectively. In this paper, values from probe $D$ are expressed as HLD, and those from probe $C$ as HLC (following the notation proposed by Wilhelm et al., 2016b). When the impact occurs between the body and the stone surface, if the initial kinetic energy is high enough then plastic deformation takes place. During compression the initial kinetic energy becomes elastic strain energy stored in the impact body, plastic strain energy which produces plastic deformation in the stone, and heat. The last two are irreversible consequently, only the elastic strain energy can be recovered as rebound kinetic energy. When the impact velocity is less than a certain value, the energy lost by plastic deformation, heat and stress wave propagation is negligible and the rebound velocity will be almost the same as the impact velocity, and the surface hardness measurement will be close to $1000 \mathrm{HL}$. On the other hand if the impact velocity is higher, more energy loss is expected and the hardness will become lower (Wu et obial, 2005). Consequently, the test result depends on the elasticity of the surface and the energy loss by plastic deformation which are both related to the mechanical strength of the material (Aoki and Matsukura, 2008). Some plastic deformation of the surface is thus a necessary consequence of a successful Equotip hardness measurement. 


\subsection{Procedure for hardness data collection and evaluation}

The hardness values have been determined using two test procedures - SIM and RIM. Single impact method (SIM): For this measurement method a number of individual measurements are taken at individual points within a sample area to produce a mean and standard deviation. In this study we have determined the appropriate SIM sample size which is large enough to portray reliably the surface hardness of the four types of sandstone and small enough to be practical for on-site application. Following Wilhelm et al. (2016b) we have taken 45 SIM measurements at random locations on each surface and calculated mean and standard deviation. Using the method of Corkum et al. (2018), we have subsampled these 45 measurements to investigate the most efficient sample size using a confidence level of $90 \%$ (black lines in figure 1). From figure 1 it can be seen that for all four sandstone types, the $90 \%$ confidence lines stabilize around a sample size of 20 , which means that this sample size gives a reliable estimate of the population mean with both $D$ and $C$ probe for the fresh stones used in this study under laboratory conditions.

Repeated impact method (RIM): For this measurement method 20 repeated impacts (successive impacts on exactly the same location) have been measured and the three highest values used to calculate the mean value (Aoki et al., 2007) which is called $H L D_{R}$ for $D$ probe and $H L C_{R}$ for $C$ probe. This has been repeated at 3 different locations on the surface of 3 different specimens for each sandstone type.

Using the Shapiro-Wilk test for normality we found that while most of our surface hardness datasets were normally distributed, some were not, and so have used both t tests and Wilcoxon tests to investigate any significant differences between SIM hardness values obtained under different conditions, and to compare mean and median for RIM hardness values.

All Equotip measurements have been taken perpendicular to the surface of the stone and perpendicular to sedimentary layers. The different experiments reported in this paper have used slightly different combinations of Equotip measurements as summarized in table 2 and described in detail below. 


\subsection{Thickness/Volume effects experiment}

To investigate the potential impacts of block thickness and specimen volume on Equotip data, we collected SIM measurements with both $C$ and D probes at 45 points on blocks of ten different sizes varying in thickness from 5 to $53 \mathrm{~mm}$ (and in volume from 14 to 200 $\mathrm{cm}^{3}$ ). For each stone type three replicate blocks were prepared for each of the ten sizes.

\subsection{Moisture effects experiment}

To investigate the potential impacts of varying block moisture contents on Equotip measurements, we used blocks of $50 \times 50 \times 50 \mathrm{~mm}$. For each type of stone, three blocks were first immersed in water under vacuum for 24 hours in order to saturate them, three other blocks were stored at $48 \% \pm 2 \% \mathrm{RH}$ for 2 months, and a further three blocks were dried at $60^{\circ} \mathrm{C}$ for $24 \mathrm{~h}$ and cooled down at room temperature $\left(20 \pm 2^{\circ} \mathrm{C}\right)$ in a desiccator at $0 \% \mathrm{RH}$ (buffered by silica gel) before measurement to create 'saturated', 'medium wet' and 'dry' blocks. Moisture contents were calculated using the gravimetric method. On each of the three replicates representing each of the three different moisture contents, 45 SIM measurements and 3 RIM measurements ( 20 impacts each time) were obtained on the top surface with both $C$ and $D$ probes.

\subsection{Surface roughness effects experiment}

To investigate the potential impacts of varying degrees of surface roughness on Equotip measurements ten samples of $50 \times 50 \times 50 \mathrm{~mm}$ of the four sandstone types have been used. In order to increase the robustness of the results we have also taken measurements on 10 blocks of four other sandstones: Bluff sandstone from Utah (Bluff), Red Sandstone from Arizona (Red Az), Sander Graser (SG) and Wustenzeller (W) sandstone from Germany. Different grades of sandpaper with average grit particle sizes ranging from 19 $\mu \mathrm{m}$ to $715 \mu \mathrm{m}$ (CAMI 500 to 30 ) were used to create varying degrees of roughness on the surface of stone blocks. 
The surface roughness on each block was measured using an optical 3D microscope (Keyence VHX6000) which has a lateral resolution of $500 \mathrm{~nm}$ (limitation of wavelength of light) and a vertical resolution of several $\mathrm{nm}$. The data have been acquired on three randomly selected zones (each $1 \times 10^{6} \mu \mathrm{m}^{2}$ in area). From those data we have extracted parameters which define the 3D surface texture (ISO 25178): Sa (arithmetic surface roughness) and $\mathrm{Sz}$ (the maximum distance from the highest point to the deepest valley). This latter gives the best estimation of the magnitude of the surface roughness and is a good indicator of surface complexity.

\subsection{Equotip $C$ and $D$ probes impacts experiment}

Although the Equotip has a much lower impact energy than devices such as the Schmidt Hammer, it might cause some damage to susceptible surfaces (which might be of concern for some valuable heritage stonework or rock art panels). An experiment has been carried out to investigate the impact of SIM and RIM on $50 \times 50 \times 50 \mathrm{~mm}$ cubes of the four sandstone types using repeat observations with the Keyence 3D microscope (collecting images and roughness measurements after 1, 5, 10 and 20 impacts on the same spot). Measurements have been collected at three locations on each surface using both $C$ and $D$ probes. Surface deformation $(\Delta \mathrm{L} / \mathrm{L})$ has been calculated from $S_{z}$ values (recorded over an area of $\left.1 \times 10^{6} \mu \mathrm{m}^{2}\right)$ using the following equation (2):

$\Delta \mathrm{L} / \mathrm{L}=-\left(\mathrm{S}_{\mathrm{z} 0}-\mathrm{S}_{\mathrm{z}}\right) / \mathrm{S}_{\mathrm{z} 0}$

Where $S z(\mu \mathrm{m})$ is defined as the sum of the largest peak height value and the largest pit depth value within the defined area, $S_{z 0}(\mu \mathrm{m})$ is the roughness before impact and $S_{z x}$ is the roughness after $x$ Equotip impacts. Negative values of $\Delta \mathrm{L} / \mathrm{L}$ imply flattening of the surface, positive values imply enhanced roughness.

\subsection{Other measurements}

Compressive strength tests have been carried out using an Instron $5885 \mathrm{H}$ universal mechanical testing machine. Ten prisms $(25 \times 25 \times 50 \mathrm{~mm})$ were tested for each type of 
sandstone and bedding direction. Specimens were loaded at a rate of $2.5 \mathrm{kN} / \mathrm{s}$. Any individual result was discarded if the average and the independent result differed by more than $30 \%$. Compressive strength was obtained by averaging at least six individual results.

The open porosity of the sandstone has been measured using the standard Rilem I.1 (EN $1936,1999-03)$ method. After drying the samples to constant mass $\left(M_{1}\right)\left(\right.$ at $\left.60^{\circ} \mathrm{C}\right)$, they were placed in desiccators, and vacuum applied for 24 hours to eliminate the air contained in the pores. Then water was slowly introduced into the vessel and the vacuum was maintained for 24 hours afterwards.

The samples were then weighed in water (i.e. hydrostatic weighing $\left(M_{2}\right)$ ) and in air $\left(M_{3}\right)$. The porosity $\left(\mathrm{N}_{\mathrm{t}}[\%]\right)$, is expressed as the ratio of the volume of the pores accessible to water to the bulk volume of the sample ( $M$ expressed in $\mathrm{g}$ ) in equation (3):

$$
\mathrm{N}_{\mathrm{t}}=\frac{M 3-M 1}{M 3-M 2} \times 100
$$

The bulk density ( $\left.\delta_{\text {bulk }}\right)$, in $\mathrm{kgm}^{-3}$, is the ratio of the mass to the bulk volume of the sample and has been calculated using the following equation (4):

$$
\mathrm{D}_{\text {bulk }}=\frac{M 1}{M 3-M 2} \times 1000
$$

\section{Results}

\subsection{Influence of sample thickness and volume}

Figure 2 summarizes the data and shows that hardness values obtained with the $C$ probe are always higher than those obtained with the $D$ probe. As explained in section 2.1 the lower impact energy of the $C$ leads to less energy dissipation by plastic deformation and consequently higher energy restitution. Moreover, probe $\mathrm{D}$ produces less scatter in the data than probe $\mathrm{C}$. 
Figure 2 also illustrates the importance of block thickness, as reliable data with probe $\mathrm{C}$ and $D$ for the four types of sandstone were only obtained from blocks thicker than $13 \mathrm{~mm}$. Measurement of hardness on blocks $<8 \mathrm{~mm}$ thick (volume $<20 \mathrm{~cm}^{3}$ ) is very difficult with probe $C$. Only $1 / 3$ of the measurements produced a successful result on $5 \pm 1 \mathrm{~mm}$ thick blocks (volume of $15.5 \pm 2.5 \mathrm{~cm}^{3}$ ) and none were obtained for $5 \mathrm{~mm}$ thick PS blocks. Only $2 / 3$ of the measurements were successful on $8 \mathrm{~mm}$ thick blocks (volume of $23.2 \pm 2.5$ ). Thin samples (5, 8 and $13 \mathrm{~mm}$ thick) should be tightly clamped, otherwise it is not possible to get more than a few valid measurements. Such samples are light and prone to strong vibrations during impact. For samples $>18 \mathrm{~mm}$ thick $\left(45 \mathrm{~cm}^{3}, 100 \mathrm{~g}\right.$ for PS, the lightest) clamping does not influence the results and is not necessary.

Figure 3 depicts probe $D$ data plotted against sample volume. Together, figures 2 and 3 show that to get representative hardness values on sandstone, samples with a minimum volume of $60 \mathrm{~cm}^{3}$, a minimum thickness of $13 \mathrm{~mm}$ and minimum weight of $100 \mathrm{~g}$ should be used. This is in agreement with Kawasaki et al. (2000) who suggested using samples with a thickness of at least $50 \mathrm{~mm}$ and Corkum et al. (2018) who recommended testing samples with a volume $\geq 90 \mathrm{~cm}^{3}$.

\subsection{Evaluation of the effects of material moisture contents}

Figure 4 illustrates the impact that block moisture content has on SIM and RIM values on all four stone types, with similar trends for both probe $D$ and probe C. Pairwise comparisons (dry vs medium, dry vs saturated, saturated vs medium) using $t$ test and Wilcoxon test on D probe SIM data all show significant differences, whereas for the $C$ probe no significant differences are found in SIM data for any of the pairs of Ohio sandstones (because of large variances), nor for dry vs saturated Stanton Moor and Locharbriggs, or dry vs medium Prague sandstone. For SIM, because water uptake is very low between dry and medium moisture contents for $\mathrm{OH}$ and PS (leading to $0.03 \% \pm$ $0.01 \%$ increase in weight) there is a corresponding reduction of surface hardness of less than $5 \%$ for the D Probe. LB and SM are the only stone types in this study with pore sizes 
lower than $0.1 \mu \mathrm{m}$ explaining their higher water uptake $(20 \% \pm 2 \%)$ under the same conditions. This corresponds to a surface hardness decrease with the $D$ probe.

From dry to saturated conditions the water uptake is $10.2 \pm 0.2 \%, 12.2 \pm 0.2 \%, 5 \% \pm 0.1 \%$ and $15.5 \pm 0.2 \%$ for $\mathrm{OH}, \mathrm{LB}, \mathrm{SM}$ and PS respectively (directly correlated to the open porosity of the stone which is $13.8 \pm 0.1 \%, 15.0 \pm 1.9 \%, 9.3 \pm 1.0 \%, 21.7 \pm 0.2 \%$ for $\mathrm{OH}$, LB, SM and PS respectively). These moisture contents increases are accompanied by nonlinear decreases in hardness values for all stones except the Prague sandstone (figure 4) with greater decrease for $D$ than $C$ probe. Indeed, the reduction in hardness values is $17 \%, 16 \%$ and $13 \%$ for $\mathrm{OH}, \mathrm{LB}$ and SM respectively (D probe) and $11 \%, 14 \%$ and $10 \%$ for $\mathrm{OH}$, LB and SM respectively ( $\mathrm{C}$ probe). These measurements are in good agreement with Schmidt hammer data collected by Sumner and Nel (2002). Conversely Prague Sandstone experiences the opposite trend with a surface hardness increase of about $10 \% \pm 2 \%$ using both $C$ and $D$ Probes between dry and saturated PS samples. The causes of this increase in surface hardness are still under investigation, but might result from the presence of incompressible water in surface voids (Ballantyne et al, 1990).

For RIM there are fewer significant differences between surface hardness values on dry and medium samples for both $C$ and $D$ probes (using a simple comparison between mean and median values +/- 30 Leeb units) - although Prague sandstone shows significant differences for both $C$ and $D$ probes. On the other hand, there are consistent and significant differences between dry and saturated samples for all stone types apart from Prague sandstone, with $20-26 \%$ lower hardness values reported for saturated stones.

These findings provide support for the qualitative, field-based observations of Viles et al. (2011) that moisture influences Equotip readings on sandstone. Ruedrich et al. (2011) also reported clear evidence of softening (strength reduction) of sandstones with varying degrees of saturation, and noted the importance of pore size and the intensity of moisture swelling to the amount of softening produced. 


\subsection{Evaluation of the effects of surface roughness}

Hardness values (mean SIM with D probe) have been collected on eight sandstones with different surface roughness characteristics as shown in figure 5 . No clear trends in hardness can be detected over $S_{z}$ values ranging from 100 to 800 microns. This finding confirms the experimental findings of Verwaal and Mulder (1993) on limestone with four different surface treatments (although they did not quantify the roughness on each of the treated surfaces). In this range roughness does not appear to influence the surface hardness measurement. This roughness range is comparable to that produced on sandstone surfaces which suffer from granular disintegration - which produces roughness on the scale of a few 100 microns (dependent on the grain size of the sandstone).

\subsection{Evaluation of the impacts of the Equotip probe on sandstone surfaces.}

In order to understand how the Equotip may damage the surface we have investigated the degree of surface deformation at the point where impact occurs on four sandstone types using SIM and RIM test methods with probe $D$ and $C(n=1,5,10,15,20)$ (Figure $6)$.

Deformation measurements using 3D microscopy after each set of impacts show that with probe $D$, surface deformation increases with the number of impacts (figure $6 \mathrm{~b}$ ). The first impact leads, for $\mathrm{OH}$, LB and SM, to a slight flattening of surface topography (negative values of deformation (Sz)) which corresponds to the crushing of asperities made by quartz grains at the surface. Unlike these three stones, PS shows deformation from the first impact caused by the penetration of the impact body into the stone (Figure $6 \mathrm{~b} 1^{\text {st }}$ impact - which is the first in the sequence on the left hand side). For SM, LB and $\mathrm{OH}$ the 3D microscope observations reveal an increasing depth of penetration of the impact body (ball) with each additional impact producing ball-shaped impact pits. For PS, the impact pits are larger and more random in shape (Figure 7). After 20 impacts of the D probe the diameter of the impact pit varies between $1150 \pm 50 \mu \mathrm{m}$ for SM up to $2300 \pm 50 \mu \mathrm{m}$ for PS, and the penetration depth of the ball from $102 \pm 20 \mu \mathrm{m}$ for SM up to $500 \pm 20 \mu \mathrm{m}$ for 
PS. The final deformation measured is inversely proportional to the UCS (Figure $6 \mathrm{~b}$ inset); i.e. the higher the UCS the lower the deformation.

Single impacts of probe $C$ on all stone types cause only minor flattening of surface topography. Repeated impacts cause obvious increase in deformation on Prague sandstone after 10 impacts (Figure 6a). In comparison, the trace mark left by probe $\mathrm{C}$ after 20 impacts is barely observable on the surface of Stanton Moor (30 $\pm 20 \mu \mathrm{m}$ in depth and $750 \pm 50 \mu \mathrm{m}$ width), whereas deeper penetration $(200 \pm 25 \mu \mathrm{m})$ and wider trace marks (1800 $\pm 50 \mu \mathrm{m}$ width) are found on Prague Sandstone (Figure 8). As reported in section 2.1 Equotip impacts lead to deformation, damaging the surface of stone with a rate depending on the impact energy of the probe used. When the body impacts the maximum pressure is at the tip contact area. The impact creates a deformation in shear and in compression with a flow zone and a plastic zone underneath. Further surface damage occurs when the plastic zone reaches the surface. The shape of that plastic zone depends on the ratio EIY ( $E$ = elastic modulus and $Y$ the Yield stress) (Fischer Cripps, 2005). This explains why damage is always higher for Prague Sandstone (which has the smallest elastic modulus $(E)$ and smaller yield stress $(\mathrm{Y}))$ than for Stanton Moor.

\subsection{Evaluation of the relationship between Equotip hardness, porosity, density and unconfined compressive strength}

As rebound response depends on the elastic properties (measured by UCS lab test method) of the stones (Aoki and Matsukura, 2007), we investigated the relation between UCS and surface hardness taking into consideration the intrinsic rock properties (i.e. porosity and bulk density) which are of great importance to the strength and deformability of stone (Figure 9).

There are clear relationships between UCS and SIM and RIM data collected from a range of sandstone types using both probe $C$ and $D$, with stronger correlations when bulk density is included (Figure 9). SIM in particular appears to be a good way of predicting 
UCS values and better than RIM for both probe $C$ and $D$ (only slightly better for $C$ ). Indeed, the use of RIM leads to compaction which changes the density and porosity (this change is still not very well understood for soft rocks). Our data confirm the relationships found by Verwaal and Mulder (1993), Corkum et al. (2018) and Price (1994) who concluded that UCS is one of the key parameters affecting hardness. Meulenkamp and Grima (1999) used the $C$ probe, rather than the $D$ probe, in their study as they found a better correlation with UCS values. We note here that the strong linear relationship between hardness value and UCS is due to the use of same rock types (sedimentary rocks) with relatively narrow UCS ranges not higher than $70 \mathrm{MPa}$.

Figure 10 illustrates the relationship between SIM and RIM values collected with $C$ and D probes and porosity. As expected, surface hardness varies inversely with porosity, with a linear trend line providing a good fit for the data (with better fit for SIM than RIM data, and better fit for SIM data collected with $C$ rather than $D$ probe).

\section{Discussion}

The appropriate numbers of readings for a robust test measurement on the sandstones studied have been evaluated through using the method of Corkum et al. (2018) as 20 for $D$ and $C$ probes. These are much smaller than the 45 readings recommended by Wilhelm et al. (2016b) for some limestones. The low number needed in this study is due to the use of unweathered sandstones of homogeneous grain size and mineralogy, cut into regular blocks.

Our data on the influence of thickness and volume for four sandstones confirms and adds a wider body of evidence to the work of Corkum et al. (2018). Indeed, our data indicate that even smaller block sizes can give reliable results. There is no difference in trend between the hardness measured with $C$ and $D$ probes across different volumes of sandstone despite the impact energy difference. This demonstrates that the decrease of the hardness for sample thicknesses lower than $13 \mathrm{~mm}$ depends on the sample weight 
and the experimental setting. Indeed the lighter the sample the more vibrations are expected.

Although the Equotip is a surface testing device, the effective monitoring of the Equotip (or the depth of sensitivity) goes somewhat deeper. Whilst we did not examine subsurface impacts directly, they can be calculated as the sum of the indentation depth and the plastic zone underneath the indentation. Wu et al. (2005) use Finite Element Analysis on the impact of a sphere with a half-space (rigid wall) and demonstrate that a sample with a minimum size of $T=2 R$ (with $R$ radius of the impact body and $T$ thickness of sample) is required for a valid result. This is in good agreement with our results and explains why it is quasi impossible to get reliable measurements on samples $<5 \mathrm{~mm}$ thick. Mesarovic and Fleck (1999) pointed out that the outer boundary conditions are unimportant from $\mathrm{T}=10 \mathrm{R}$. This might explain why in our study blocks $>15 \mathrm{~mm}$ thickness $(10 R)$ show no variation of surface hardness measurements.

Our data shows that measurements on similar quartz arenitic sandstones blocks with a volume more than $60 \mathrm{~cm}^{3}$, a thickness of at least $15 \mathrm{~mm}$, a minimum weight of $100 \mathrm{~g}$ should give reliable results and we recommend clamping samples strongly if they are in the lower range.

Our research provides the first quantitative evidence from a range of sandstones that the Equotip is affected by moisture contents of the blocks measured. The effects can be significant, especially for RIM measurements on saturated blocks where readings can be up to $26 \%$ lower on saturated than on dry blocks. This is in good agreement with Siedel (2010) and Hawkins and McConnell (1992), who have shown that sedimentary rocks can lose up to $50 \%$ in UCS from dry to saturated conditions. The degree of sensitivity to moisture content is mostly controlled by the proportions of quartz and clay minerals present (Hawkins and McConnell, 1992). All the sandstones tested are affected in the same way apart from Prague Sandstone which shows no clear trends with moisture contents (and even some evidence of increased SIM values on saturated blocks) which might be related to its high clay content. These findings mean that, where possible, Equotip measurements should be carried out on dry blocks. Where controlling moisture contents is not possible, the moisture status of blocks and rock surfaces used for Equotip 
measurements should be measured and reported (perhaps using handheld microwave measuring device which are not significantly influenced by salt contents) and care taken in comparing data between wet and dry surfaces.

Our data also provide the first clear quantitative evidence that surface roughness between 100 and 800 microns (absolute difference between highest and lowest points) has no significant influence on Equotip hardness measurements on sandstone taken with the $D$ probe. This result is important and encouraging for both geomorphological and heritage science applications of the Equotip. Further research could usefully investigate whether this finding is also true for the $C$ probe, for the $D$ probe over a higher range of roughness degrees, and for other stone types.

As surface hardness of the tested stones has been shown to be linearly related to their open porosity, the rebound test could provide a simple method to assess the degree of rock weathering. Different types of deterioration like disintegration, scaling, blistering and cracks lead to an increase of voids (porosity). This could be detected by a decrease of hardness measured by Equotip. Conversely, the formation of patina and encrustations (compact, hard layers adhering to the stone) will harden the surface and can be highlighted by harder values from the rebound test.

Our data on the correlation between Equotip measurements, porosity, compressive strength and bulk density, implies that surface hardness can be used as a proxy for both open porosity and compressive strength. For the sandstones tested, we find that SIM data collected with the $\mathrm{C}$ probe provides the best estimate of open porosity.

The impact energy of the $D$ probe is one order of magnitude higher than the $C$ probe. Consequently, more energy is lost from plastic deformation of the stone in shear, in the compressive stress field beneath the indenter, reducing the hardness value. This is confirmed by the observation and measures done with 3D microscope where the 
deformation induced by the $D$ probe is higher than the $C$ probe and increases with the number of impacts.

Table 3 summarises the comparative strengths and weaknesses of the $C$ vs. the $D$ probe. Whilst the pits produced by the Equotip probe are small (up to $2.3 \mathrm{~mm}$ in diameter for the Prague Sandstone) they can be unsightly on heritage surfaces and are likely to be longlasting. Given the lower damage produced by the $C$ probe this should be the default option for use on heritage sandstone surfaces of great value. On the other hand, to extract valid data from the rebound test, the impact body has to deform the surface. Indeed, the absolute value for hardness was the least value of pressure beneath a spherical indenter necessary to produce a permanent mark at the center of the area of contact, (Hertz 1882 cited in Fischer Cripps 2005)). This is not always the case with Probe C (except for PS). Whichever probe is selected it is important to present the data with helpful notation so that readers are clear which probe was used. There are significant differences between HLC and HLD measurements from the same stone surfaces (see table 1 for a summary).

Our results provide interesting comparisons with data collected from other stone types. For example, Wilhelm et al. (2016b) found much more variable data (and thus a need for much larger sample sizes) from four different British building limestones. These authors also found some similar advantages of the $\mathrm{DL}$ over the $\mathrm{D}$ probe (notably providing a better correlation with open porosity).

\section{Conclusions}

The Equotip is confirmed to be a suitable method for evaluating surface hardness (and for estimating porosity and compressive strength) on four types of sandstone. We have demonstrated that smaller samples can be reliably evaluated than previously found, and for the first time have shown that the data produced are not significantly affected by surface roughness up to $800 \mu \mathrm{m}$. However, the moisture status of the stone or rock surface under study has been found to be a potentially important factor influencing the results produced and thus needs to either be controlled or recorded when Equotip data are collected. 
These results are of significance to many geomorphological and heritage science applications, where similar quartz arenite rocks with varying degrees of porosity and matrix characteristics are found. The focus in this research on laboratory-based experiments on freshly cut samples of sandstones means that our results are not influenced by environmental and other factors which beset many field-based studies. So, whilst the results are not directly transferable to many field settings (where long progress of weathering, biological growths etc makes stone and rock surfaces much more complex than the cut faces we studied), we can have higher confidence in them than more variable datasets collected from field exposures (e.g. Viles et al., 2011) and they can provide the basis for future field-based studies. Carrying out measurements perpendicular to the bedding direction (as we have done in this research) ensures that the data is relevant in many situations in natural and built environments (e.g. shore platform surfaces, boulder surfaces, coping stones) and comparable to measurements of compressive strength measurement which are all done perpendicular to the bedding layers.

For heritage science applications, such as before and after testing of the properties of sandstones treated with consolidants and other conservations treatments, the results presented in this paper demonstrate the utility of the Equotip. Where accelerated weathering and application of consolidants is likely to influence the roughness of samples, our results demonstrate that this will not influence the hardness values obtained. Good correlation between Equotip measurements on the studied stones and compressive strength measurements means that the Equotip can provide a proxy for the destructive UCS testing, allowing repeat testing of exactly the same samples before and after treatment and weathering.

For geomorphological applications, such as exploring the degrees of weathering on surfaces, and calculating exposure ages across sandstone shore platforms, cliff faces and boulder surfaces, our results demonstrate that the Equotip can generate meaningful data, but that care needs to be taken to collect data properly. The discovery that a sample size of around 20 SIM measurements is adequate to gain a reliable estimate of the surface hardness on unweathered blocks of the sandstones studied confirms that the Equotip can generate useful data quickly (although further testing is required on rougher, 
naturally weathered sandstone surfaces). The importance of moisture contents in influencing Equotip values on most of the sandstones studied, means that considerable care needs to be taken in field-based geomorphological applications. Making inferences about weathering status and exposure age from Equotip values can only be done where the confounding influence of moisture contents can be accounted for. Further research is needed on other rock types to assess whether moisture contents are similarly important.

\section{References}

ASTM D5873-14, "Standard Test Method for Determining of Rock Hardness by Rebound Hammer Method", American Society for Testing and Materials, Philadelphia, United States, 2014

Aly N, Hamed A, Gómez Heras M, Benavente D,Álvarez de Buergo M. 2016. The effect of salt crystallisation on the mechanical properties of limestone: statistical correlation between non-destructive and destructive techniques. In: Hughes, J., \& Howind, T. (Eds.) Science and Art: A Future for Stone: Proceedings of the 13th International Congress on the Deterioration and Conservation of Stone. Paisley: University of the West of Scotland, 2016. Vol. I. ISBN 978-1-903978-57-3, pp. 225-231.

André M.F, Voldoire O, Vautier F, Roussel E, Phalip B, Morel D. 2014. Impact of cement repointing on rates of sandstone decay in medieval churches of the French Massif Central. Geological Society, London, Special Publications, 391(1):157-174.

Aoki H, Matsukura, Y. 2007. A new technique for non-destructive field measurement of rock-surface strength: an application of the Equotip hardness tester to weathering studies. Earth Surface Processes and Landforms, 32(12):1759-1769.

Aoki H, Matsukura, Y. 2008. Estimating the unconfined compressive strength of intact rocks from Equotip hardness. Bulletin of Engineering Geology and the Environment, 67(1):23-29.

Asiri Y, Corkum A, El Naggar H. 2016. Leeb hardness test for UCS estimation of sandstone. Canadian Geotechnical Society:3-5. 
Ballantyne CK, Black NM, Finlay DP, 1990. Use of the Schmidt test hammer to detect enhanced boulder weathering under late-lying snowpatches. Earth Surface Processes and Landforms, 15: 471-474.

Coombes MA, Feal-Pérez A, Naylor LA, Wilhelm K. 2013. A non-destructive tool for detecting changes in the hardness of engineering materials: Application of the Equotip durometer in the coastal zone. Engineering Geology, 167:14-19.

Corkum AG, Asiri Y, El Naggar H, Kinakin D. 2018. The Leeb Hardness Test for rock: An updated methodology and UCS Correlation. Rock Mechanics and Rock Engineering, 51(3):665-675.

EN 1936, 2006 - Natural stone test methods. Determination of real density and apparent density and of total and open porosity, 2006-03.

Feal-Pérez A, Blanco-Chao R. 2013. Characterization of abrasion surfaces in rock shore environments of NW Spain. Geo-Marine Letters, 33(2-3):173-181.

Fischer Cripps AC. 2005 Introduction to contact mechanics. New York: Springer.

Frank, S., \& Schubert, H. 2002. Portable hardness testing- principles and applications. Journal of Nondestructive Testing, 7(10), 8

Hawkins AB, McConnell BJ. 1992. Sensitivity of sandstone strength and deformability to changes in moisture content. Quarterly Journal of Engineering Geology and Hydrogeology. 25: 115-130.

ISO, 25178-2: 2012. Geometrical product specifications (GPS)— Surface texture: A real-Part 2: Terms, definitions and surface texture parameters

Kawasaki S, Yoshida M, Tanimoto, C, Masuya T. 2000. The Development of Property Evaluation Materials Based on the Simple Rebound Hardness Test. Jour. Japan Soc. Eng. Geol. 41: 230-241.

Leeb DH. 1978. New dynamic method for hardness testing of metallic materials. VDIReport. 308:123-128. 
Menéndez B. 2016. Non-Destructive Techniques Applied to Monumental Stone Conservation, In: F.P. García Márquez (Ed.), Non-Destructive Testing, InTech, DOI: $10.5772 / 62408$.

Mesarovic SD, Fleck NA. 1999. Spherical indentation of elastic-plastic solids. Proc.R.Soc.London. A455: 2707-2728

Meulenkamp F, Grima MA. 1999. Application of neural networks for the prediction of the unconfined compressive strength (UCS) from Equotip hardness. International Journal of Rock Mechanics and Mining Sciences, 36(1):29-39.

Okawa S, Ohoka M, Funato A. 1999. Application of hardness tester to rock specimens. In: Proceedings of the 29th symposium of rock mechanics (pp. 256-260).

Perez Ema N, Bustamante Montoro RA. 2013. Integrated studies for the evaluation of conservation treatments on stone material from archaeological sites. Application to the case of Mérida (Spain). International Journal of Conservation Science, 4(spec):693-700.

Ruedrich J, Bartelsen,T, Dohrmann R, Siegesmund S. 2011. Moisture expansion as a deterioration factor for sandstone used in buildings. Environmental Earth Sciences, 63(78):1545-1564.

Siedel H. 2010. Historic building stones and flooding: changes of physical properties due to water saturation. J Perf Constr Fac 24:452-461.

Siegesmund S, Snethlage R. 2011. Stone in Architecture, Properties, Durability. SpringerVerlag ( $4^{\text {th }}$ eds) Berlin Heidelberg.

Sumner P, Nel W, 2002. The effect of rock moisture on Schmidt hammer rebound: tests on rock samples from Marion Island and South Africa. Earth Surface Processes and Landforms. 27:1137-1142.

Torok A, Prikryl R. 2010. Current methods and future trends in testing, durability analyses and provenance studies of natural stones used in Historical Monument. Engineering Geology. 115: 139-142. 
Verwaal W, Mulder, A., 1993. Estimating rock strength with the Equotip hardness tester. International Journal of Rock Mechanics and Mining Sciences \& Geomechanics Abstracts 30(6):659-662.

Viles H, Goudie A, Grab S, Lalley J. 2011. The use of the Schmidt Hammer and Equotip for rock hardness assessment in geomorphology and heritage science: a comparative analysis. Earth Surface Processes and Landforms, 36(3):320-333.

Wedekind W, Pötzl C, Doncel RL, Platz TV, Siegesmund S. 2016. Surface hardness testing for the evaluation of consolidation of porous stones. In: Hughes, J., \& Howind, T. (Eds.) Science and Art: A Future for Stone: Proceedings of the 13th International Congress on the Deterioration and Conservation of Stone. Paisley: University of the West of Scotland, 2016. Vol. I. ISBN 978-1-903978-57-3, pp.491-499.

Wilhelm K, Viles H, Burke O, Mayaud J. 2016a. Surface hardness as a proxy for weathering behaviour of limestone heritage: a case study on dated headstones on the Isle of Portland, UK. Environmental Earth Sciences, 75(10):931.

Wilhelm K, Viles H, Burke, Ó. 2016b. Low impact surface hardness testing (Equotip) on porous surfaces-advances in methodology with implications for rock weathering and stone deterioration research. Earth Surface Processes and Landforms, 41(8): 1027-1038. Wu CY, Li LY, Thornton C. 2005. Energy dissipation during normal impact of elastic and elastic-plastic sphere. International Journal of impact Engineering, 32: 593-604

Yilmaz NG. 2013. The influence of testing procedures on uniaxial compressive strength prediction of carbonate rocks from Equotip Hardness Tester (EHT) and proposal of a new testing methodology: hybrid dynamic hardness $(\mathrm{HDH})$. Rock Mechanics and Rock Engineering, 46(1): 95-106.

Zornoza-Indart A, Lopez-Arce P. 2016. Silica nanoparticles $\left(\mathrm{SiO}_{2}\right)$ : Influence of relative humidity in stone consolidation. Journal of Cultural Heritage, 18:258-270. 
Table 1. Summary information (UCS: Unconfined compressive strength, HLD hardness in leeds with D probe, HLC hardness in leeds with $C$ probe) on the four stone types used in this research.

\begin{tabular}{|l|l|l|l|l|l|l|}
\hline Sandstone & $\begin{array}{l}\text { UCS } \\
(\mathrm{MPa})\end{array}$ & $\begin{array}{l}\text { HLD } \\
(\text { mean } \\
\text { and sd })\end{array}$ & $\begin{array}{l}\text { HLC } \\
(\text { mean } \\
\text { and sd })\end{array}$ & $\begin{array}{l}\text { Porosity } \\
(\%) / \text { Class }\end{array}$ & $\begin{array}{l}\text { Bulk } \\
\text { Density } \\
\left(\mathrm{kg} / \mathrm{m}^{3}\right)\end{array}$ & $\begin{array}{l}\text { Clay } \\
\text { contents } \\
(\%)\end{array}$ \\
\hline $\begin{array}{l}\text { Stanton } \\
\text { Moor }\end{array}$ & $60 \pm 9$ & $601 \pm 51$ & $697 \pm 59$ & $12.9(1)$ & 2323 & $<2$ \\
\hline Ohio & $36 \pm 2$ & $436 \pm 52$ & $492 \pm 66$ & $20(2)$ & 2084 & 3.5 \\
\hline Locharbriggs & $26 \pm 4$ & $456 \pm 40$ & $485 \pm 86$ & $23.4(3)$ & 2070 & 3.75 \\
\hline Prague & $17 \pm$ & $327 \pm 49$ & $364 \pm 75$ & $28.9(3)$ & 1878 & 8 \\
\hline
\end{tabular}


Table 2: Experimental design including block dimensions and numbers of replicates for each experiment.

\begin{tabular}{|c|c|c|c|c|c|c|}
\hline \multirow[t]{2}{*}{ Experiment } & \multirow[t]{2}{*}{$\begin{array}{l}\text { Block dimensions } \\
\text { (replicates) }\end{array}$} & \multicolumn{4}{|c|}{$\begin{array}{l}\text { Equotip } \\
\text { measurement } \\
\text { modes }\end{array}$} & \multirow[t]{2}{*}{ Other observations } \\
\hline & & C & D & SIM & RIM & \\
\hline $\begin{array}{l}\text { Volume/ } \\
\text { thickness } \\
\text { effects }\end{array}$ & $\begin{array}{l}10 \text { different } \\
\text { thicknesses from } 14 \\
\mathrm{~cm}^{3} \text { to } 200 \mathrm{~cm}^{3}(3 \\
\text { replicates of each } \\
\text { size }\end{array}$ & $X$ & $x$ & $X$ & & $\begin{array}{l}\text { Samples clamped to lab } \\
\text { bench on rubber mat. } \\
\text { Measurements done on } \\
\mathrm{OH}, \mathrm{LB}, \mathrm{SM}, \mathrm{PS}\end{array}$ \\
\hline $\begin{array}{l}\text { Moisture } \\
\text { effects }\end{array}$ & $\begin{array}{l}50 \times 50 \times 50 \mathrm{~mm}(3 \\
\text { replicates) }\end{array}$ & $x$ & $x$ & $x$ & $\mathrm{X}$ & $\begin{array}{l}\text { Measurements done on } \\
\mathrm{OH}, \mathrm{LB}, \mathrm{SM}, \mathrm{PS}\end{array}$ \\
\hline Roughness & $\begin{array}{l}3 \text { surface roughness } \\
\text { measurements } \\
\text { covering an area of } \\
1 \times 10^{6} \text { to } 1 \times 10^{7} \mu \mathrm{m}^{2} \\
\text { (10 replicates) }\end{array}$ & D & $\mathrm{X}$ & $\mathrm{X}$ & & $\begin{array}{l}\text { Keyence 3D microscope } \\
\text { Measurements done on } 8 \\
\text { types of sandstone OH, LB, } \\
\text { SM, PS, Red Az, Bluff, SG, } \\
\text { W. }\end{array}$ \\
\hline UCS & $\begin{array}{l}10 \text { replicates of each } \\
\text { type of sandstones } \\
(25 \times 25 \times 50 \mathrm{~mm})\end{array}$ & & & & & $\begin{array}{l}\text { Measurements done on } 8 \\
\text { types of sandstone OH, LB, } \\
\text { SM, PS, Red Az, Bluff, SG, } \\
\text { W. }\end{array}$ \\
\hline Porosity & $\begin{array}{l}10 \text { replicates } \\
(50 \times 50 \times 50 \mathrm{~mm})\end{array}$ & & & & & $\begin{array}{l}\text { Measurements done on } 8 \\
\text { types of sandstone OH, LB, } \\
\text { SM, PS, Red Az, Bluff, SG, } \\
\text { W. }\end{array}$ \\
\hline Deformation & $\begin{array}{l}3 \text { replicates } \\
(50 \times 50 \times 50 \mathrm{~mm})\end{array}$ & $X$ & $\bar{X}$ & $\bar{X}$ & $\mathrm{X}$ & $\begin{array}{l}\text { Keyence 3D microscope } \\
\text { observations of surface } \\
\text { after } 0,1,5,10,15 \text { and } 20 \\
\text { repeated impacts. } \\
\text { done on } 8 \text { types of } \\
\text { sandstone OH, LB, SM, PS, } \\
\text { Red Az, Bluff, SG, W. }\end{array}$ \\
\hline
\end{tabular}


Table 3: Comparison between $\mathrm{C}$ and $\mathrm{D}$ probes.

\begin{tabular}{|l|l|l|}
\hline & C & D \\
\hline Impact energy (Nmm) & 3 & 11.5 \\
\hline $\begin{array}{l}\text { Visible impact on } \\
\text { sandstone surfaces (SIM) }\end{array}$ & No & Yes \\
\hline $\begin{array}{l}\text { SIM Impact on surface } \\
\text { roughness/ deformation }\end{array}$ & Slight flattening & Flattening/roughening \\
\hline $\begin{array}{l}\text { RIM impact on surface } \\
\text { roughness/ deformation }\end{array}$ & $\begin{array}{l}\text { Yes, slight } \\
\text { penetration }\end{array}$ & Yes, penetration \\
\hline $\begin{array}{l}\text { Influenced by volume/ } \\
\text { thickness/weight } \\
\text { (<60 cm }{ }^{3}<15 \text { mm, }< \\
100 g)\end{array}$ & Yes & Yes \\
\hline $\begin{array}{l}\text { Sample size needed to } \\
\text { give good estimate of } \\
\text { mean for SIM }\end{array}$ & 20 & 20 \\
\hline $\begin{array}{l}\text { Predictor of open porosity } \\
\text { (SIM) }\end{array}$ & V good & Good \\
\hline Predictor of UCS (SIM) & V Good & V Good \\
\hline
\end{tabular}



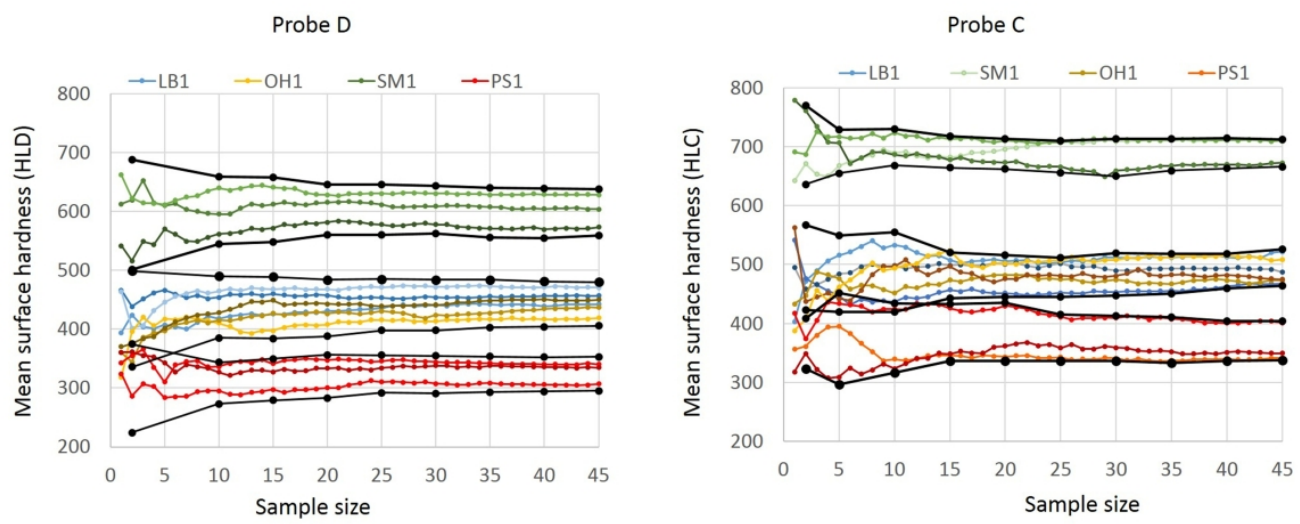

Figure 1: Increase of accuracy associated with including a greater number of impact (sample size) in the mean test result obtained with (left) D probe and (Right) C probe following the method of Corkum et al., (2017). See text for further explanation.

$337 \times 138 \mathrm{~mm}(300 \times 300 \mathrm{DPI})$ 

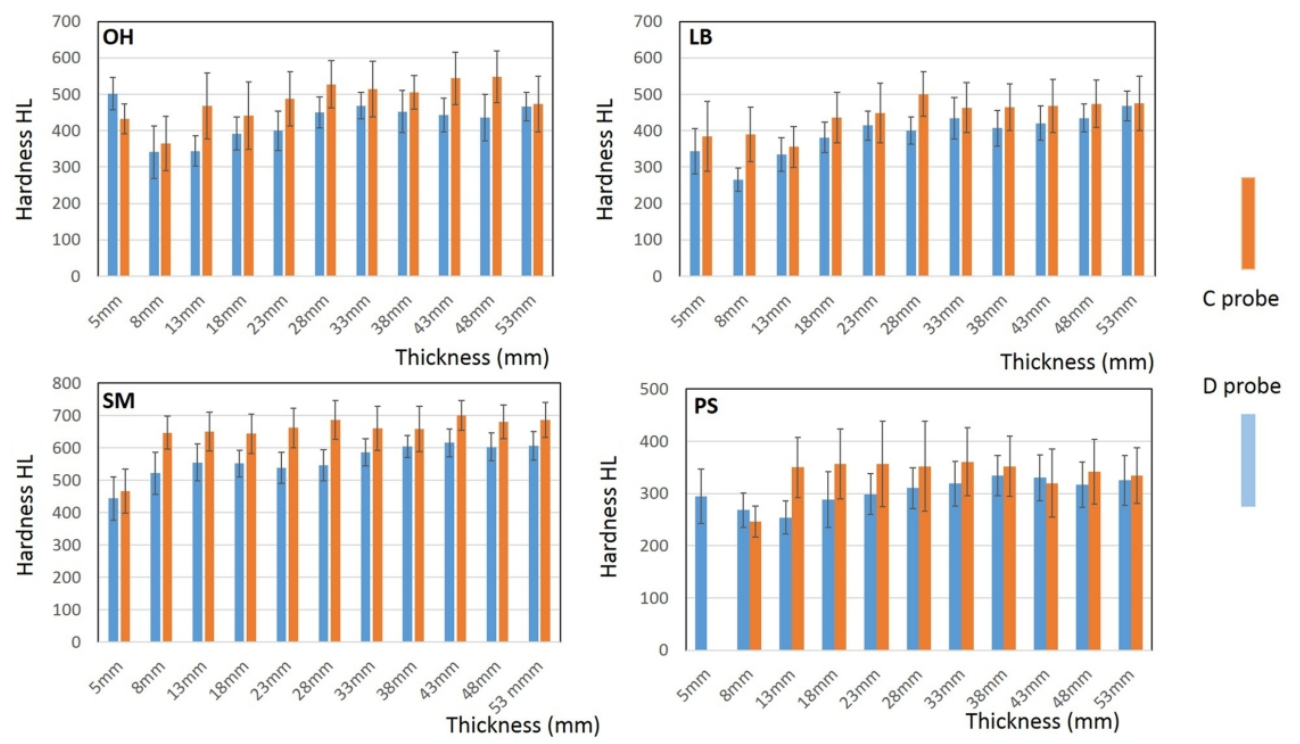

Figure 2: Surface hardness ( $C$ and $D$ probes) for different thicknesses of stone.

$200 \times 115 \mathrm{~mm}(300 \times 300 \mathrm{DPI})$ 


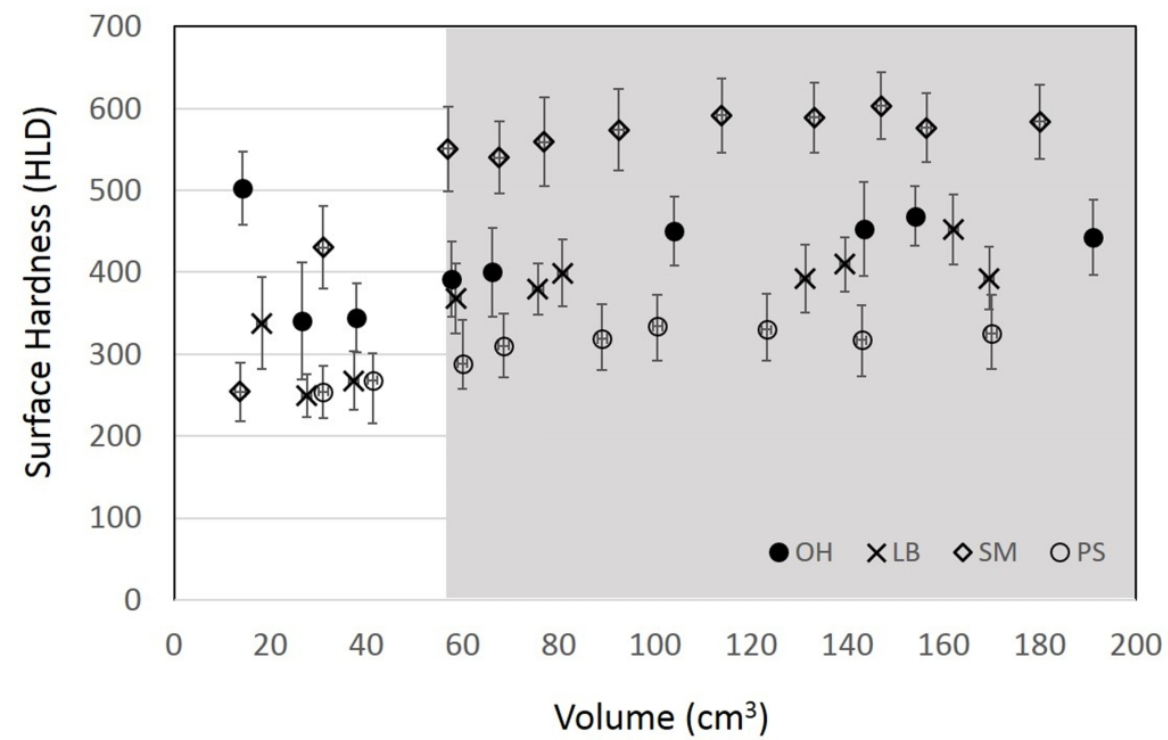

Figure 3: Surface Hardness (Probe D) for different sample volumes ( $48 \pm 2 \% \mathrm{RH}$ and $20 \pm 2{ }^{\circ} \mathrm{C}$ ). $211 \times 128 \mathrm{~mm}(300 \times 300$ DPI) 

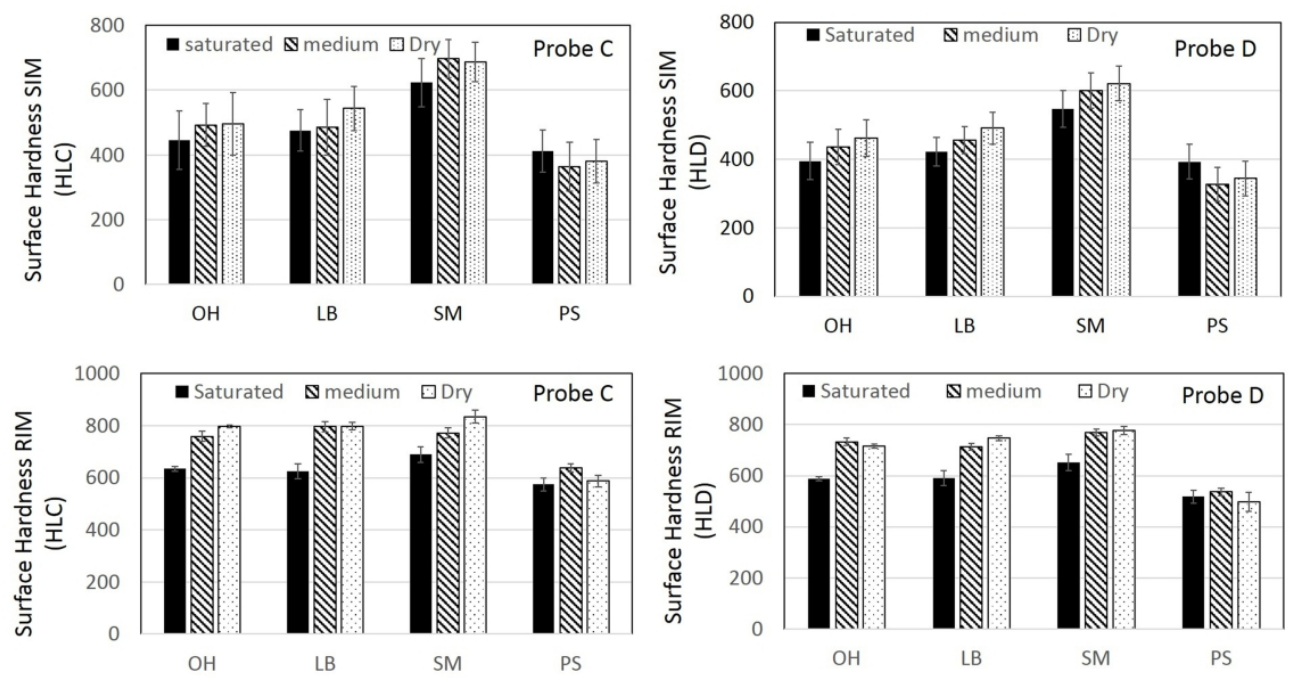

Figure 4: Surface hardness of Ohio sandstone, Locharbriggs, Stanton Moor and Prague Sandstone containing different moisture contents (top) SIM obtained with probe C and D (bottom) RIM obtained with probe C and D.

$227 \times 119 \mathrm{~mm}(300 \times 300$ DPI $)$ 


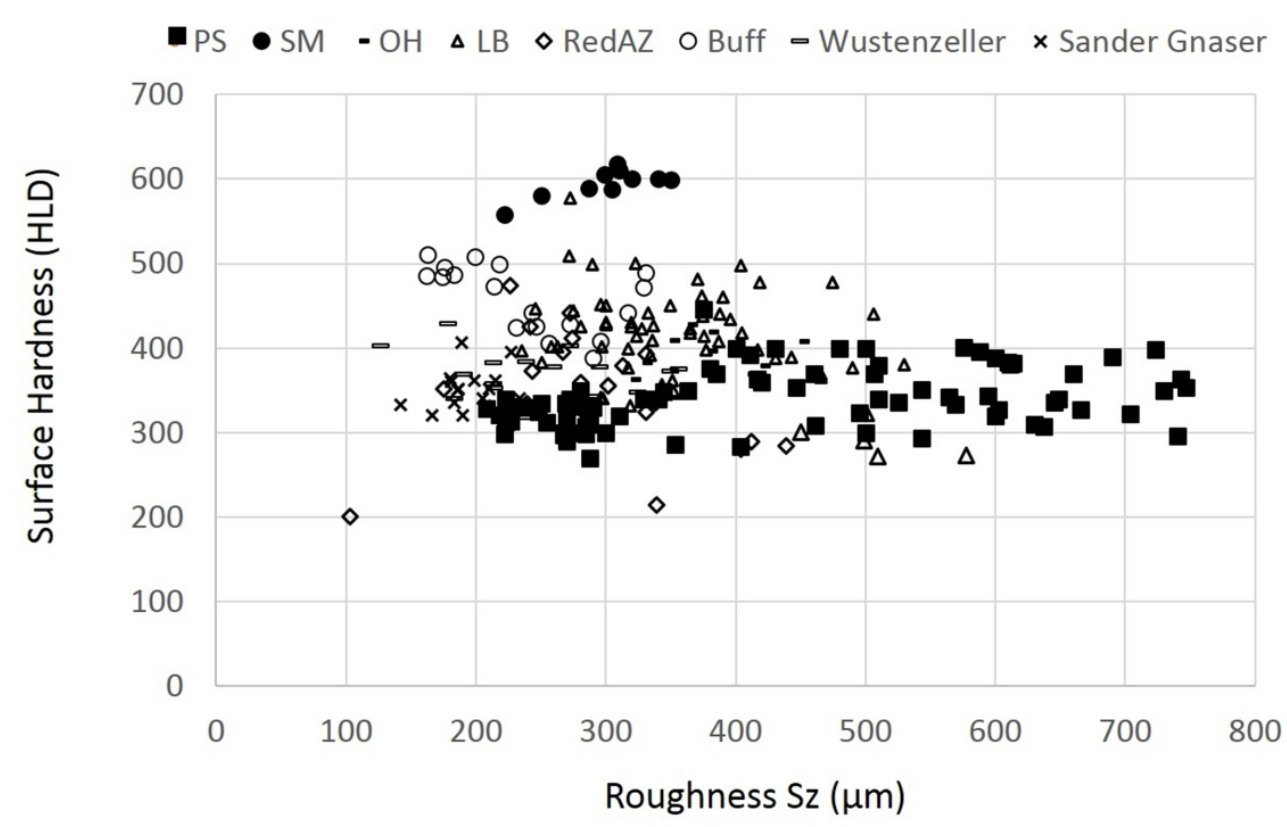

Figure 5: Surface hardness of 8 different types of sandstone measured with a probe $D$ vs surface roughness $(\mathrm{Sz})$.

$209 \times 136 \mathrm{~mm}(300 \times 300 \mathrm{DPI})$ 

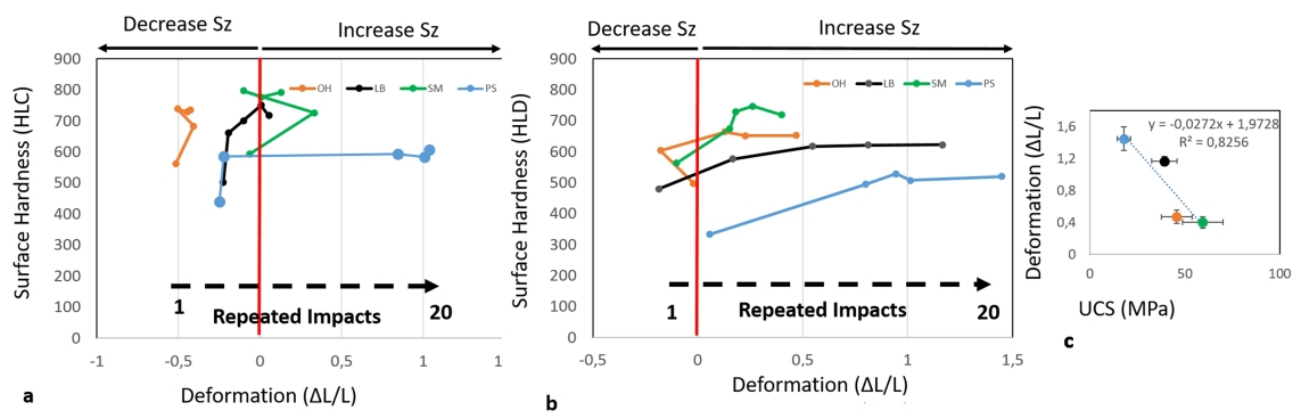

Figure 6: Surface deformation (Sz) at the point of Equotip probe impact of Ohio Sandstone, Locharbriggs, Stanton Moor and Pragie Sandstone after 1, 5, 10, 15, 20 impacts (a) with probe C (b) with probe D. (c) Surface deformation (depth of indentation) plotted against uniaxial compressive strength of the 4 sandstones.

$364 \times 123 \mathrm{~mm}(300 \times 300$ DPI $)$ 
Figure 7: 3D microscope representations of the surface topography at the site of Equotip probe impacts of (A) Stanton Moor and (B) Prague Sandstone after a single impact (1), 10 repeated impacts (10) and 20 repeated impacts (20) with probe $D$. In each image, blue is low, red is high and the vertical scale bars indicate the differences in heights represented by the topography shown (in microns). 


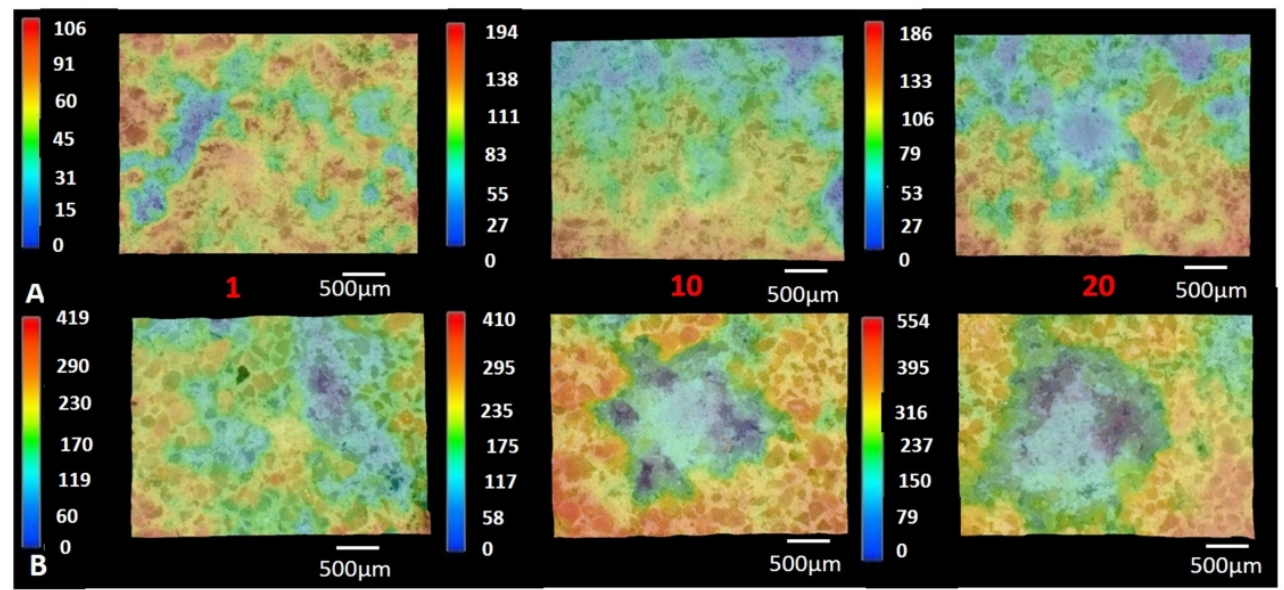

Figure 8: 3D microscope representations of the surface topography at the site of Equotip probe impacts of (A) Stanton Moor and (B) Prague Sandstone after a single impact (1), 10 repeated impacts (10) and 20 repeated impacts (20) with probe $C$. In each image, blue is low, red is high and the vertical scale bars indicate the differences in heights represented by the topography shown (in microns). 

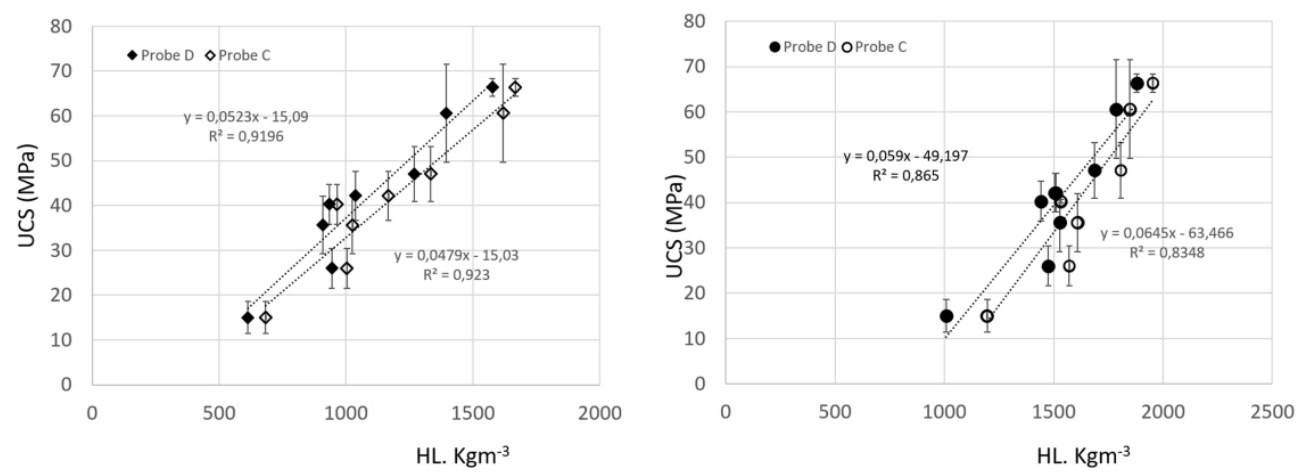

Figure 9: UCS (MPa) plotted against surface hardness $x$ density (left) SIM (right) RIM with probe D filled markers and probe $\mathrm{C}$ unfilled markers.

$337 \times 135 \mathrm{~mm}(300 \times 300 \mathrm{DPI})$ 


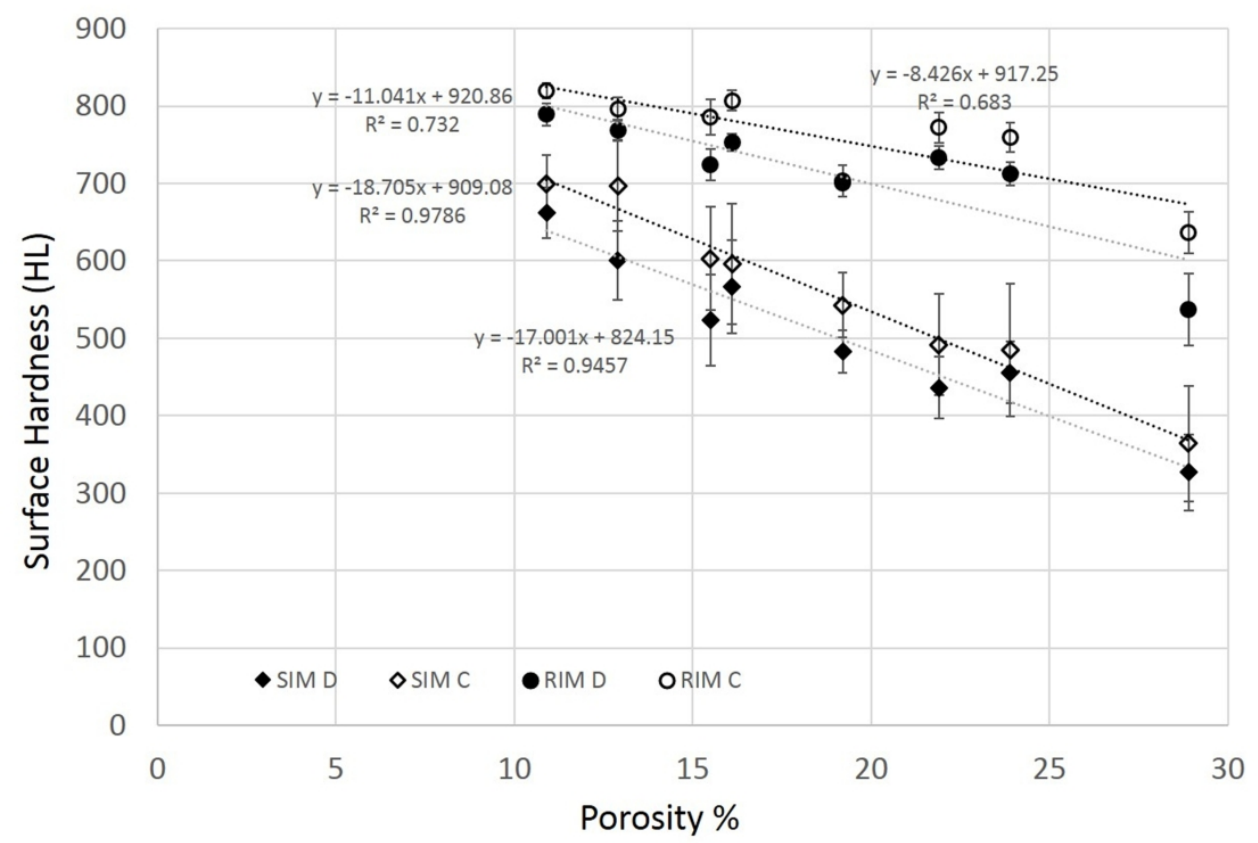

Figure 10: Surface hardness measured with the probe $C$ and $D$ by the single impact test method and the repeated impact test method on Sandstone with different porosities.

$217 \times 145 \mathrm{~mm}(300 \times 300$ DPI $)$ 
Figure 1: Increase of accuracy associated with including a greater number of impact (sample size) in the mean test result obtained with (left) D probe and (Right) C probe following the method of Corkum et al., (2017). See text for further explanation.

Figure 2: Surface hardness ( $C$ and D probes) for different thicknesses of stone.

Figure 3: Surface Hardness (Probe D) for different sample volumes ( $48 \pm 2 \% \mathrm{RH}$ and $20 \pm 2^{\circ} \mathrm{C}$ ).

Figure 4: Surface hardness of Ohio sandstone, Locharbriggs, Stanton Moor and Prague Sandstone containing different moisture contents (top) SIM obtained with probe $C$ and D (bottom) RIM obtained with probe $C$ and $D$.

Figure 5: Surface hardness of 8 different types of sandstone measured with a probe $D$ vs surface roughness (Sz).

Figure 6: Surface deformation (Sz) at the point of Equotip probe impact of Ohio Sandstone, Locharbriggs, Stanton Moor and Pragie Sandstone after 1, 5, 10, 15, 20 impacts (a) with probe C (b) with probe D. (c) Surface deformation (depth of indentation) plotted against uniaxial compressive strength of the 4 sandstones.

Figure 7: 3D microscope representations of the surface topography at the site of Equotip probe impacts of (A) Stanton Moor and (B) Prague Sandstone after a single impact (1), 10 repeated impacts (10) and 20 repeated impacts (20) with probe $D$. In each image, blue is low, red is high and the vertical scale bars indicate the differences in heights represented by the topography shown (in microns).

Figure 8: 3D microscope representations of the surface topography at the site of Equotip probe impacts of (A) Stanton Moor and (B) Prague Sandstone after a single impact (1), 10 repeated impacts (10) and 20 repeated impacts $(20)$ with probe $C$. In each image, blue is low, red is high and the vertical scale bars indicate the differences in heights represented by the topography shown (in microns).

Figure 9: UCS (MPa) plotted against surface hardness $x$ density (left) SIM (right) RIM with probe D filled markers and probe $\mathrm{C}$ unfilled markers.

Figure 10: Surface hardness measured with the probe $C$ and $D$ by the single impact test method and the repeated impact test method on Sandstone with different porosities. 